https://doi.org/10.38129/Ann.Yur.Ist.2020.4.4.80

УДК 347.23(332.2):347.233:347.233.5

\title{
ВЛИЯНИЕ СОЦИАЛИСТИЧЕСКОЙ СИСТЕМЫ ПРАВА НА СТАНОВЛЕНИЕ СОВРЕМЕННОГО ПРАВА СОБСТВЕННОСТИ И СБЕРЕЖЕНИЙ
}

\author{
ЮЛИЯ ГАВРИЛЬЧЕНКО (Минск, Республика Беларусь) *
}

Развитие сберегательной традиции в советский период обусловливался, в первую очередь, марксистско-ленинским подходом к собственности и проходил в достаточно сложных условиях. У классиков марксизма-ленинизма можно найти следующее высказывание по поводу сбережений: «...расширение воспроизводства выступает как превращение прибыли в капитал и как сбережения капиталиста, который, вместо того, чтобы проесть полученный даром прибавочный продукт, делает его снова средством эксплуатации труда» ${ }^{1}$. В.И. Ленин на этот счет высказывается еще более категорично: «Частная собственность - это грабеж, и государство, основанное на частной собственности, есть государство хищников»².

Начало советского периода отмечается уничтожением дореволюционного сберегательного дела. В соответствии с Декретом ВЦИК от 14 (27) декабря 1917 г. «О национализации банков» ${ }^{3}$ банковская деятельность объявляется государственной монополией. Основным направлением в экономическом развитии предполагается курс на полное устранение денег из хозяйственного оборота, натурализация, продразверстка и непосредственное распределение продовольствия и промтоваров.

Учитывая значение сберегательных касс, они формально сохраняются (в отличие от коммерческих банков). Однако при решении вопроса о

${ }^{1}$ Маркс, К., Энгельс, Ф. Сочинения / К. Маркс, Ф. Энгельс, 2-е изд. - М. : Политиздат, 1964. - T. 26. - Ч. 3. - С. 283.

2 Ленин, В.И. Полное собрание сочинений. 5-е изд. / В.И. Ленин : в 55 т. - М. : Изд-во полит. лит., 1981. - Т. 41. - С. 352.

${ }^{3}$ О национализации банков : Декрет ВЦИК от 14 (27) декабря 1917 г. // Библиотека нормативно-правовых актов Союза Советских Социалистических республик [Электронный ресурс] / Режим доступа: http://www.libussr.ru. - Дата доступа: 25.02.2019. 
дальнейшей судьбе привлеченных в сберкассы вкладов формулируется так называемый «классовый принцип». Хранящиеся в сберкассах средства, приобретенные «нетрудовым путем», подлежат конфискации. Критерии определения «нетрудового» характера отсутствовуют, тайна сбережений фактически отменяется.

В соответствии с декретом СНК РСФСР об аннулировании государственных займов (декабрь 1917 г.) и после запрета выдавать суммы, внесенные до 1 января 1918 г., сберегательные кассы фактически прекращают операции. В период «военного коммунизма» они сливаются с Народным банком РСФСР (1919 г.), затем вновь восстанавливаются в качестве самостоятельных учреждений в связи с проведением денежной реформы (1923 г.). Поскольку обесцененные дореволюционные сбережения не компенсируются и никаких гарантий государство не предоставляет, можно сказать, что сберегательное дело $b$ течение первых послереволюиионных лет оказалось уничтоженным.

Тем не менее, советское государство остро нуждается в ресурсах. В 20-е гг. XX в. начинается восстановление финансово-кредитной системы, в связи с чем предпринимается ряд организационно-правовых мер. Издаются важные акты в области сбережений: Постановление СНК РСФСР от 26 декабря 1922 г. «Об учреждении государственных сберегательных касс» и Положение Совнаркома от 27 декабря 1922 г. «О государственных трудовых сберегательных кассах».

В 1923 г. в структуре союзного наркомата финансов создается Главное Управление государственных трудовых сберегательных касс, призванное восстановить сберегательное дело на новых началах. В этот период социальная и другие функции сбережений уходят на второй план, первостепенное значение уделяется их инвестиционной роли в народном хозяйстве. Предполагается, что трудовые сберкассы должны аккумулировать свободные средства населения и использовать их для решения широкомасштабных хозяйственных задач.

Впоследствии принимается ряд актов, реформирующих деятельность сберегательных касс. В частности, Положением Совнаркома СССР от 27 ноября 1925 г. «О государственных трудовых сберегательных кассах СССР» 4 закрепляется монопольное положение государства в сберегательном деле,

\footnotetext{
4 Положение о государственных трудовых сберегательных кассах Союза Советских Социалистических Республик, утв. ЦИК СССР, СНК СССР, 27 нояб. 1925 г. // Библиотека нормативно-правовых актов Союза Советских Социалистических республик [Электронный ресурс] / Режим доступа: http ://www.libussr.ru/doc_ussr/ussr_2751.htm. - Дата доступа : 25.02.2019.
} 
конкретизируются услуги и льготы, предоставлявшиеся вкладчикам. В Положении о гострудсберкассах, утвержденном в 1929 г. ${ }^{5}$, государственные трудовые сберкассы становятся единым кредитным учреждением страны, управление которым сосредоточивается в руках союзного Наркомфина.

В годы Великой Отечественной войны большое значение приобретают вкладные операции полевых учреждений Госбанка, работникам которых поручено провести разъяснительную работу среди офицеров Советской Армии. Сберегательные кассы способствуют мобилизации денежных средств населения для финансирования военных расходов, принимают активное участие в размещении предназначенных для этого госзаймов, а также в распространении билетов денежно-вещевых лотерей.

Благодаря патриотическому подъему, объем вкладов в сберкассах в военный период даже вырастает. Многие граждане размещают свои средства во вклады с расчетом сохранить их. Этому не мешают ни тяжелая экономическая и политическая ситуация, ни ограничения для выдачи сбережений, которые вводятся уже на второй день войны и действуют до января 1944 г.

В период войны сеть сберкасс сокращается примерно вдвое. Однако ее восстановление происходит уже к 1952 г. Вскоре после войны, в конце 1947 г., отменяются карточки и проводится денежная реформа, которая носит по сути конфискационный характер, но для вкладчиков сберкасс предусматриваются определенные льготы. Ведется активная пропаганда вкладных операций.

В послевоенное время, в соответствии с Уставом Государственных трудовых сберегательных касс, утвержденным постановлением Совета Министров СССР от 20 ноября 1948 г. 6, сберкассы становятся неотъемлемой частью государственного аппарата. Вкладчикам предоставляются определенные гарантии права личной собственности.

К концу 50-х гг. XX в. происходит постепенный переход от преимущественно принудительных (фактически обязательные госзаймы,

5 Положение о государственных трудовых сберегательных кассах Союза Советских Социалистических Республик, утв. постановлением ЦИК СССР, СНК СССР, 20 февр. 1929 г. // Библиотека нормативно-правовых актов Союза Советских Социалистических республик [Электронный ресурс] / Режим доступа: http :/ / www.libussr.ru. - Дата доступа : 25.02.2019.

6 Устав государственных трудовых сберкасс СССР, утв. пост. Совмина СССР, 20 нояб. 1948, № 4339 // Библиотека нормативно-правовых актов Союза Советских Социалистических республик [Электронный ресурс] / Режим доступа: http :/ / www.libussr.ru. - Дата доступа : 25.02.2019. 
которые можно отнести к сбережениям лишь условно) к добровольным сбережениям. В результате повышения уровня жизни населения и создания элементарных предпосылок к образованию сбережений, с 60-х. г2. ХХ в. фрормирование традииий сбережения проходит достаточно быстрыми темпами (на фоне низкого уровня исходной базы).

В Гражданском кодексе УССР 1963 г. и аналогичном Гражданском кодексе БССР 1964 г. уже содержится ряд норм, регулирующих договор банковского вклада, гарантируются тайна вкладов, сохранность вкладов, право вкладчика на доход. С 1965 по 1983 гг. сумма вкладов в СССР вырастает с 18.7 до 186.8 млрд руб. ${ }^{7}$. К началу 80-х гг. ХХ в. сберегательные кассы подразделяются на несколько типов: центральные кассы, кассы первого и второго разряда, агентства сберегательных касс.

В исследуемый период определяется тенденция расширения универсальности сберкасс. Последнии Устав сберегательных касс, утвержденный Советом Министров СССР в 1977 г., устанавливает, что государственные трудовые сберегательные кассы принимают вклады, осуществляют безналичные расчеты, прием платежей, размещают государственные внутренние займы СССР, производят продажу и покупку облигаций, принимают участие в проведении лотерей и выплате выигрышей, выдают именные аккредитивы и т.д. Сберкассы все больше сближаются по сути с банками, что $b$ конечном итоге приводит к преобразованию системы государственных трудовых сберегательных касс в Сбербанк СССР (1988 г.). Переподчинение сберкасс Госбанку СССР происходит еще в 1963 г.

Кроме сбережений в сберкассах, доминирующих в советский период, гражданам доступны также приобретение ценных бумаг СССР и вклады в организации госстрахования по договорным (накопительным) видам личного страхования. В советский период такой вид сбережений, как страхование жизни к совершеннолетию или к бракосочетанию получает большое распространение. Как правило, он предусматривает вложение 1 тыс. руб. под 3 \% годовых. K началу 80-x гг. ХХ в. до 80 \% потенииального контингента по страхованию жизни к совершеннолетию имели соответствующий полис ${ }^{8}$.

7 Коломин, Е.В., Бабашкин, Л.Е., Захаров, В.С. Финансы и кредит СССР / Е.В. Коломин, Л.Е. Бабашкин, В.С. Захаров. - М. : Финансы и статистика, 1984. - С. 151. 8 Веремеев, В.В. Система гарантий сохранения сбережений населения в полисах страхования жизни : дис. ... канд. экон. наук : 08.00.10 / В.В. Веремеев. - М. : Рос. эконом. акад. им. Г.В. Плеханова, 2008. - С. 25. 
Таким образом, можно отчасти согласиться с Н. П. Шерстневой, которая отмечает, что «в целом в послереволюционный период развитие сберегательного дела приобрело статус государственного приоритета» 9 . В это время ведется активная пропаганда организованных сбережений, которая имеет ощутимые результаты. В ряде случаев заимствования у населения приобретают негласную обязательность (приобретение облигаций госзаймов руководящими работниками). В ранний послевоенный период пропаганда вкладных операций достигает такого уровня, что «человек, не подписавшийся на заем, подвергался общественному осуждению за корыстные интересы и нежелание помочь молодому государству»10.

Вместе с тем, применительно к данному времени нельзя говорить о полноценном развитии сберегательного дела и, особенно, сберегательной культуры, поскольку в регулировании приоритетными остаются публичные интересы. Например, в Конституциях БССР и УССР 1937 г. ${ }^{11}$ (ст. 5) и 1978 г. (ст. 10) 12 говорится о таких формах социалистической собственности как государственная (общенародная) и кооперативно-колхозная (de facto этот сектор также является элементом государственной экономики). Объявляется право

9 Шерстнева, Н.П. История сберегательного дела в России в XVIII - XX веках и роль частных вкладов в формировании пассивной базы банков : автореф. дис. ... канд. экон. наук : 08.00.01 / Н.П. Шерстнева. - СПб. : Санкт-Петербургск. гос.ун-т экон. и финансов, 2005. - С. 19.

10 Шерстнева, Н.П. История сберегательного дела в России в XVIII - XX веках и роль частных вкладов в формировании пассивной базы банков : автореф. дис. ... канд. экон. наук : 08.00.01 / Н.П. Шерстнева. - СПб. : Санкт-Петербургск. гос.ун-т экон. и финансов, 2005. - С. 19.

11 Конституция (Основной закон) БССР от 19 февраля 1937 г. // Национальный правовой интернет-портал Беларуси [Электронный ресурс]. - 2019. - Режим доступа : http ://old.pravo.by/lawhistory/konst_1937.htm. - Дата доступа: 22.02.2019; Конституция (Основной закон) УССР от 30 января 1937 г. // Українська Радянська Соціалістична Республіка [Электронный ресурс]. - 2019. Режим доступа: http://ycсp.pф/konstitutsiya-ussr/5-konstitutsiya-ukrainskoj-ssr-1937-goda.html.- Дата доступа : 22.02.2019.

12 Конституция (Основной закон) БССР от 14 апреля 1978 г. // Национальный правовой интернет-портал Беларуси [Электронный ресурс]. - 2019. - Режим доступа : http :/ / www.pravo.by/main.aspx?guid=2081. - Дата доступа : 22.02.2019; Конституция (Основной закон) БССР от 20 апреля 1978 г. // Українська Радянська Соціалістична Республіка [Электронный ресурс]. - 2019. Режим доступа: http:/ /yсcp.pф/konstitutsiya-ussr/7-konstitutsiya-ukrainskoj-ssr-1978-goda.html.- Дата доступа : 22.02.2019. 
личной собственности граждан на их трудовые доходы и сбережения, на жилой дом и подсобное домашнее хозяйство, на предметы домашнего хозяйства и обихода, на предметы личного потребления и удобства (ст. 10 Конституции 1937 г. и ст. 13 Конституции 1978 г.). Отдельно отмечается, что имущество, находящееся в личной собственности или в пользовании граждан, не должно служить для извлечения нетрудовых доходов, поскольку источником роста общественного богатства благосостояния народа и каждого советского человека является только свободный от эксплуатации труд советских людей (ст. 13-14 Конституции 1978 г.).

Подавление частно-правового начала и сдерживание сберегательной традиции проявляются (кроме ограничения частной собственности и ее правового непризнания) в искусственном установлении низкого уровня текущего дохода, изъятии значительной части дохода в виде налогов и отчислений, отсутствии широкого выбора форм вложения сбережений и др. Социализм как государственный строй, при котором нет богатых, не предусматривает уважения к сбережениям и стимулирования их наращивания. Социалистическая мораль исходит из того, что сбережения результат проявления «далеко не лучших качеств человека: расчетливости, склонности к денежному накопительству»13.

Таким образом, в советское время в области сбережений складывается противоречивая ситуация. С одной стороны, наблюдается активный рост организованных сбережений, постоянное увеличение суммы и количества вкладов в сберкассах, расширение сети сберкасс. В условиях политики общего отрицательного отношения к сбережениям, направленной на уменьшение у населения возможности сберегать, важным приоритетом становится вовлечение в государственную кредитно-финансовую систему любых свободных денежных средств. К началу 90-х гг. ХХ в. пассивы Сберегательного банка более чем на 90 \% формировались за счет денежных сбережений населения.

С другой стороны, специалисты отмечают, что существенную часть сбережений составляют вклады до востребования, не носящие сберегательного характера14. При этом общий объем сбережений все равно остается не очень высоким: в начале 80-х гг. XX в. сумма вкладов в Сбербанке немногим

13 Зайцев, А. Личные сбережения трудящихся при развитом социализме / А. Зайцев // Вопросы экономики. - 1980. - № 3. - С. 54-61. С. 54.

14 Логунов, В.В. Эволюция сберегательного поведения россиян в условиях становления рыночной экономики : дис. ... канд. социол. наук : 22.00 .03 / В.В. Логунов. - М. : Финансовая академия при Правительстве РФ, 2003. - С. 89. 
превышает сумму доходов за пять месяцев. Для сравнения, домашние хозяйства США в 1998 г. обладают 5-летним запасом средств относительно текущего потребления населением товаров и услуг.

В силу экономической ситуации сбережения нередко представляют собой вынужденные резервы, вызванные дефицитом в сфере потребительских товаров. Несбалансированность на потребительском рынке впервые проявляется в 1966 г., после того, как в результате экономической реформы заработная плата обретает «стимулирующую функцию». Рост зарплаты начинает значительно опережать рост производительности труда. Дисбаланс потребительского рынка нарастает и в 1988 г. неудовлетворительный спрос на товары и услуги составляет уже 70 млрд руб. или $20 \%$ объема годового розничного товарооборота. В то же время, к концу 1988 г. накапливается почти на 1 млрд руб. неходовых товаров, не отвечающих спросу населения ${ }^{15}$.

Переломным моментом в развитии советского общества и государства становится «перестройка» (80-е гг. XX в.). Кризис «реального социализма», очевидная неэффективность социалистической экономики и ухудшение общего положения на фоне снижения цен на нефть, являющейся источником валютных поступлений, порождают острую необходимость экономических и политических реформ.

В процессе «перестройки» возникает качественно новое направление развития в банковской сфере - появляются первые негосударственные коммерческие и кооперативные банки. Особо важное влияние на это оказывает принятие 27 июля 1987 г. постановления ЦК КПСС и Coвета Министров СССР «О совершенствовании системы банков в стране и усилении их воздействия на повышение эфрфективности экономики»16, 26 мая 1988 г. - Закона «О кооперации $b$ СССР»17, 1 сентября 1988 г. - постановления Совета Министров СССР «Об

15 Станишевская, Н.М. Денежные доходы населения как фактор товарно-денежной сбалансированности / Н.М. Станишевская // Управление социальным развитием региона / [М.В. Никитенко, О.В. Сивограков, А.Б. Гаврилов и др.] ; Науч. ред. М.В. Никитенко; АН БССР, Ин-т экономики. - Минск : Навука и тэхніка, 1990. - С. 45-50.

16 О совершенствовании системы банков в стране и усилении их воздействия на повышение эффективности экономики: постановление ЦК КПСС и Совета Министров СССР, 27 июл. 1987 г., № 821 // Консультант Плюс : Версия Проф. Технология 3000 [Электронный ресурс] / ООО «ЮрСпектр». - М., 2019.

17 О кооперации в СССР : Закон СССР, 28 мая 1988 г., № 8998-XI // Консультант Плюс : Версия Проф. Технология 3000 [Электронный ресурс] / ООО «ЮрСпектр». M., 2019. 
утверждении устава Государственного банка СССР»18, 31 марта 1989 г. постановления Совета Министров СССР № 280 «О переводе государственных специализированных банков СССР на полный хозяйственный расчет и самофинансирование»19.

Верховным Советом СССР 11 декабря 1990 г. принимаются законы «О Государственном банке СССР» ${ }^{20}$ и «О банках и банковской деятельности» 21 , которые устанавливают двухуровневую банковскую систему в виде Центрального банка (Госбанка), Сберегательного банка и коммерческих банков. Коммерческие банки получают самостоятельность в проведении кредитной политики, в привлечении вкладов, при определении процентных ставок. Также они обретают право осуществлять валютные операции на основе лицензии Центрального банка. Госбанк получает новые полномочия - он начинает контролировать деятельность коммерческих банков путем установления нормативных требований.

Новая политическая элита от «ускорения социально-экономического развития страны» переходит к провозглашению гласности, узаконению частного предпринимательства, признанию частной собственности основой гражданского общества. Названные преобразования создают правовые предпосылки для развития сбережений и повышения инвестиционной роли последних.

В самом начале реформирования уровень сбережений советских граждан возрастает. Хотя увеличивается и роль сбережений в форме наличных денег, склонность к организованным сбережениям, прежде всего в виде банковских вкладов, по-прежнему остается высокой. К 1991 г. у многих людей на сберегательных книжках находятся значительные суммы денег. Часть

18 Об утверждении устава Государственного банка СССР : постановление Совета Министров СССР, 1 сент. 1988 г., № 1061 // Консультант Плюс: Версия Проф. Технология 3000 [Электронный ресурс] / ООО «ЮрСпектр». - М., 2019.

19 О переводе государственных специализированных банков СССР на полный хозяйственный расчет и самофинансирование : постановление Совета Министров СССР, 31 авг. 1989 г., № 280 // Консультант Плюс : Версия Проф. Технология 3000 [Электронный ресурс] / ООО «ЮрСпектр». - М., 2019.

20 О Государственном банке СССР : Закон СССР, 11 дек. 1990 г., № 1828-1 // Консультант Плюс : Версия Проф. Технология 3000 [Электронный ресурс] / ООО «ЮрСпектр». - М., 2019.

21 О банках и банковской деятельности: Закон СССР, 11 дек. 1990 г., № 1829-1 // Консультант Плюс : Версия Проф. Технология 3000 [Электронный ресурс] / ООО «ЮрСпектр». - М., 2019. 
вкладчиков выражает надежду, что по мере рыночных преобразований сможет начать свое собственное дело в сфере малого и среднего бизнеса. Однако последующие события вносят существенные коррективы в эти планы.

Начало современному этапу развития сбережений в Украине, Беларуси и Российской Федерации положил распад СССР и появление независимых постсоветских государств. При этом, в первые годы суверенности на фоне политических преобразований ситуация в народном хозяйстве резко ухудшилась. Нашим новым государствам пришлось столкнуться с глубоким экономическим кризисом, сложной политической ситуацией, возрастающими социальными проблемами.

Инфлячия привела к обесиенению организованных сбережений населения по различным данным в 3000-5000 раз. Это усугубило тяжелое положение. После распада СССР вклады населения в учреждениях Сберегательного банка были оформлены каждой страной как внутренний государственный долг. Начиная с 1991 г. неоднократно предпринимались попытки компенсации потерь от обесценения вкладов. Проведенный автором анализ нормативных правовых актов и практики их применения $b$ данной сорере 22 свидетельствует, что Беларусь и Украина вошли в число государств, в которых проблема компенсаиии советских вкладов достойного решения так и не получила. В результате доверие населения к государственным финансовым институтам сильно пошатнулось.

Аналогичная ситуация произошла в сфере страхования жизни. В результате невыполнения обязательств по договорам, заключенным Госстрахом СССР, и отсутствия компенсаций по ним система накопительного страхования утратила доверие граждан и была по сути разрушена. Попытки восстановления популярности накопительного страхования проводились неоднократно, но былого успеха не получили.

Обесценение вкладов почти полностью уничтожило самое ценное приобретение советского периода в сберегательной сфере - привычку граждан хранить сбережения в организованной форме. Со временем вопрос о компенсации советских вкладов несколько сгладился, однако его нерешенность оказала серьезное негативное влияние на формирование сберегательной культуры. В результате весь постсоветский период, и особенно его первое десятилетие, характеризуется ростом доли неорганизованных сбережений.

22 Гаврильченко, Ю.П. Теоретические основания и правовой механизм регулирования сбережений населения / Ю.П. Гаврильченко. - Минск : Медисонт, 2015. - 288 c. 
С развитием рыночных отношений проявилась еще одна отрицательная тенденция: возникли общие условия для снижения ценности сбережений как таковых. Расслоение общества, появление класса «богатых» на фроне общего обеднения населения создали новый эталон человека как иччности предприимчивой, успешной и состоятельной. Данный идеал сформировался в качестве образа, которому нужно соответствовать прямо сейчас (искажение западной модели успеха как результата деловых качеств и вложенных, как правило, многолетних усилий).

Таким образом, в современный период, на фоне свершившегося закрепления права частной собственности намечается общии уход от сберегательной культуры $\kappa$ культу потребления. Молодое поколение, открыв для себя возможности потребления, перестает видеть смысл в кропотливом накоплении. В быстро меняющихся условиях предполагается, что успех должен быть стремительным. При этом низкий уровень экономической и финансовой грамотности не позволяет сформировать адекватную модель поведения, провоцирует участие в высокорискованных финансовых операциях.

В связи с расширением рынка финансовых услуг активно развивается право частных финансов (в наибольшей степени в виде банковского права). При этом инвестиционная значимость сбережений в современных условиях становится едва ли не определяющей в контексте государственного регулирования сберегательного процесса. Поэтому правовое воздействие, по-прежнему формируемое отношением к частной собственности, выходит за пределы частно-правового. В рамках отдельного исследования мы доказываем, что $b$ настоящее время гражданское право не может полноценно регулировать банковские и частнофинансовые правоотношения, т.к. последние не в полной мере соответствуют приниииу юридического равенства сторон ${ }^{23}$.

В современный период, когда социальная значимость сбережений презюмируется вследствие полноценного исполнения ими инвестиционной роли, а кредитно-финансовая система активно развивается, происходит постепенное становление самостоятельного сберегательного права, которое со временем сможет стать полноценной отраслью, объединяющей совокупность правовых норм, регулирующих сберегательные отношения на основании сочетания методов юридического равенства и властного подчинения. Низкая обеспеченность экономики долгосрочными инвестициями, недостаточность механизмов трансформации сбережений в инвестиции в условиях становления культа потребления и низкой финансовой грамотности

23 Довнар, Ю.П. Банковское право. Общая часть / Ю.П. Довнар. - Минск : Амалфея, 2006. - 310 c. C. $5-11$. 
населения требуют дальнейшего совершенствования законодательства в области сбережений, развития сберегательного дела и сберегательного права на фоне упрочнения права частной собственности и развития механизмов его защиты.

Dr. habil. Prof. Julia Gavrilchenko (Minsk, Belarus)

The Influence of the Socialist System of Law on the Formation of Modern Property Rights and Savings

The article considers the problem of the formation of savings cultures of the population of the USSR. The author draws attention to the regulatory and legal support of savings banks, public financial accumulation and insurance systems. It is claimed that the work of the institutions preceding the savings banks of the USSR had a generally positive effect on the further development of the financial and economic culture of Soviet citizens. However, parallel measures aimed at curbing people's private aspirations have led to a paradoxical increase in financial ignorance in society. Its worst manifestations became apparent during the period of so-called "perestroika" when the ideal of cumulative success shifted towards the ideal of dangerous rapid enrichment.

Key words: Socialist Law, Financial Savings, Savings Business, Savings Banks, Savings Culture, Consumption.

Доктор юридических наук Юлия Гаврильченко (Минск, Беларусь)

Влияние социалистической системы права на становление современного права собственности и сбережений

В статье рассматривается проблема формирования сберегательные культуры населения СССР. Автор обращает внимание на нормативно-правовое обеспечение работы сберегательных касс, системы государственного финансового накопления и страхования. Утверждается, что работа учреждений, предшествующих Сбербанку СССР, произвела в целом положительный эффект на дальнейшее развитие финансово-экономической культуры советских граждан. Однако, параллельные мероприятия, направленные на сдерживание частнособственнических устремлений людей, привели к парадоксальному нарастания финансового неграмотности в обществе. Ее худшие проявления стали очевидными в период так называемой «перестройки», когда идеал накопительного успеха сместился в сторону идеала опасного стремительного обогащения. 
Ключевые слова: социалистическое право, финансовые накопления, сберегательные дело, сберегательные кассы, сбережения, сберегательная культура, потребительство.

Доктор юридичних наук Юлія Гаврильченко (Мінськ, Білорусь)

Вплив соціалістичної системи права на становлення сучасного права власності та заощаджень

У статті розглядається проблема формування зберігальної культури населення СРСР. Автор звертає увагу на нормативно-правове забезпечення роботи зберігальних кас, системи державного фінансового накопичення та страхування. Стверджується, що робота установ, передуючих Ощадному банку СРСР, справила загалом позитивний ефект на подальший розвиток фінансовоекономічної культури радянських громадян. Однак, паралельні заходи, спрямовані на стримування приватновласницьких прагнень людей, призвели до парадоксального наростання фінансової неграмотності в суспільстві. Її найгірші прояви стали очевидними в період так званої «перебудови», коли ідеал накопичувального успіху змістився вбік ідеалу небезпечного стрімкого збагачення.

Ключові слова: соціалістичне право, фінансове накопичення, зберігальна справа, зберігальні каси, заощадження, зберігальна культура, споживацтво.

* Гаврильченко Юлия Петровна - доктор юридических наук, профессор, профессор кафедры финансового права и правового регулирования хозяйственной деятельности юридического факультета Белорусского государственного университета в Минске.

E-mail: yuliyadovnar@rambler.ru. 